\title{
Bringing order to polymers
}

\author{
The discovery of catalysts that dictated polymer sterochemistry, which earned a Nobel prize for \\ KarlZiegler and Giulio Natta 50 years ago, initiated the modern age of controlled polymer synthesis.
}

One could tell the history of the twentieth century through polymers. In a weird way that is almost what American author Thomas Pynchon attempted in his novel Gravity's Rainbow, which shows the German cartel IG Farben clandestinely orchestrating the Second World War and making rockets with unnerving, sensory polymer skins. But the truth is scarcely less strange and no less dominated by the agencies of conflict, commerce and politics.

Karl Ziegler, who 50 years ago won the Nobel Prize in Chemistry alongside Italian chemist Giulio Natta for their work on the stereoselective catalysis of alkene polymerization $^{1,2}$, began studying polymer synthesis during the Second World War to make artificial rubber for the German war effort because supplies from the Asian rubber plantations were cut off. When the war ended Ziegler was in Halle, soon to become Russian-occupied territory, and the American authorities encouraged him to take a post at Mülheim to preserve his expertise for the West. It was there in 1953 that he discovered the organometallic compounds, such as triethylaluminium, that would not only catalyse ethylene polymerization at lower temperatures and pressures than the standard industrial process then prevailing, but would produce orderly straight-chain molecules without random branching, creating a high-density product with new potential uses ${ }^{3}$.

Natta, working in Milan, was also drawn into synthetic-rubber work during the war, and once he heard about Ziegler's discovery he realized that it could be used to make ordered polymers from other alkenes. He and his co-workers quickly discovered that ethylaluminium chloride and vanadium tetrachloride would catalyse the formation of polypropylene with a stereoregular (isotactic) chain structure ${ }^{4}$ : that is, all the methyl side-chains are on the 'same' side, enabling orderly crystalline packing into a solid, high-density form. The Italian chemicals company Montecatini, which funded Natta's research, immediately developed this process on an industrial scale, and were marketing isotactic polypropylene at Ferrara by 1957 as a bulk plastic, a fibre and a packing film. Natta went on to conduct pioneering work on the synthesis of rubbers by controlled polymerization of butadiene.

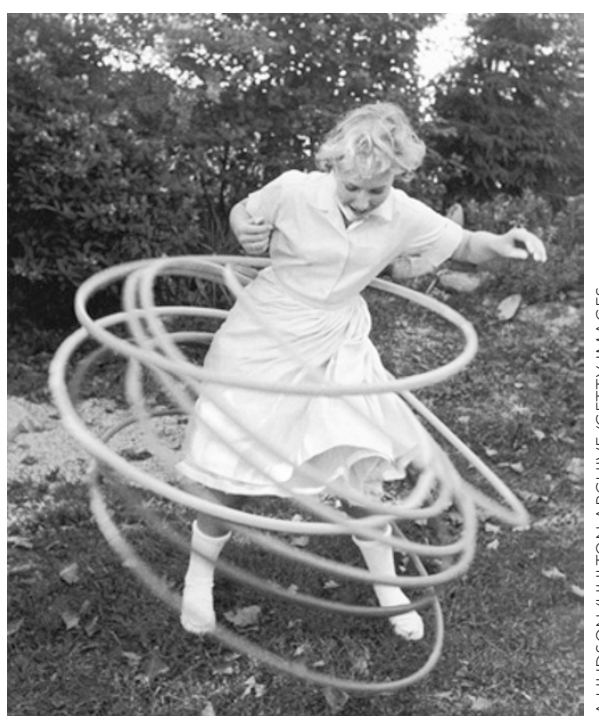

Yet this is not the full extent of the priority dispute, for Alexander Zeltz and Ron Carmody of Standard Oil in Indiana also made a partially crystalline isotactic form of polypropylene in 1950 using a molybdenum catalyst. But there's more to a discovery than being first: it's not clear that they knew quite what they had made, and in any case there were complex questions to be addressed about the degree of stereoselectivity created by the different catalysts ${ }^{5}$.

Basic science is here more the beneficiary than the begetter, for the work of Ziegler and Natta pointed the way to approaches for the stereoselective formation of carbon-carbon bonds, which remains a rich field of science today. The value of their synthetic strategy has occasionally surfaced in unexpected ways - it was an inadvertent excess of Ziegler-Natta catalyst, for example, that led Hideki Shirakawa to discover the first electrically conducting polymer, a form of polyacetylene, in Tokyo in 1967. The scale of the polyolefin industry, meanwhile, scarcely needs emphasizing: close to 50 million tonnes of polypropylene alone is produced each year.

One moral of these stories is that true discovery requires that you know what you've done, and show it. But they also reveal how the conventional narrative of technological advance, whereby 'pure', curiosity-driven fundamental science leads to applications, is seldom of much relevance in fields such as materials chemistry. Social and cultural drivers often determine what gets explored - if not necessarily what comes out. And technological success may be determined by the fickle whims of the market rather than the merit of the product. One might add the lesson that, to achieve recognition, one should also publish quickly and get a good lawyer - not perhaps the most edifying moral, but that's the way of the world.

\footnotetext{
References

1. http://www.nobelprize.org/nobel_prizes/chemistry/ laureates/1963/ziegler-lecture.pdf

2. http://www.nobelprize.org/nobel_prizes/chemistry/ laureates/1963/natta-lecture.pdf

3. Ziegler, K., Holzkamp, E., Breil, H. \& Martin, H. Angew. Chem 67, 541-547 (1955)

4. Natta, G. et al. J. Am. Chem. Soc. 77, 1708-1710 (1955)

5. Pino, P. \& Moretti, G. Polymer 28, 683-692 (1987).
} 